\title{
Non-insulin Hypoglycemic
}

National Cancer Institute

\section{Source}

National Cancer Institute. Non-insulin Hypoglycemic. NCI Thesaurus. Code C80511.

Any substance, other than insulin, used to treat hyperglycemia. 